\title{
Efisiensi sistem informasi berbasis online dalam pengumpulan rpkps mata kuliah Untuk pengembangan kompetensi program studi
}

\author{
Bayu Febriadi ${ }^{1}$, Nurliana Nasution ${ }^{2}$ \\ ${ }^{1}$ Program Studi Sistem Informasi Fakultas Ilmu Komputer Universitas Lancang Kuning \\ ${ }^{2}$ Program Studi Teknik Informatika Fakultas Ilmu Komputer Universitas Lancang Kuning \\ Jl. Yos Sudarso KM. 8 Rumbai, Pekanbaru, Riau, telp. 08117532015 \\ e-mail: ${ }^{1}$ bayufebriadi9@gmail.com, ${ }^{2}$ nurliana_2006@yahoo.co.id
}

\begin{abstract}
Abstrak
Informasi berbasis komputer sangat berpengaruh pesat dalam dunia kerja, begitu juga halnya sistem informasi berbasis web dimanfaatkan sebagai sarana peningkatan informasi. Pemanfaatan tersebut akan mempermudah suatu pekerjaan seperti halnya pe ngolahan data lebih cepat, keputusan yang akan diambil lebih tepat, menghemat waktu dan biaya. Selain itu, sistem informasi yang berbasis web juga dapat menjadi sarana promosi yang efesien dan sumber informasi yang dapat diakses oleh pengguna internet yang semakin lama semakin luas. Pada Fakultas Ilmu Komputer belum adanya media sebagai sarana dalam pengumpulan RPKPS matakuliah sementara penerapan komputer dan internet maupun sumber daya sudah ada, sehingga diktat mata kuliah yang diberikan dosen pengampu terhadap kompetensi program studi tidak sesuai dan untuk pengembangan kompetensi program studi. Adapun metode yang digunakan dengan mengumpulkan data-data yang ada dan menganalisa permasalahan dalam pengumpulan dan penyesuaian RPKPS dengan menyesuaikan dengan kurikulum yang sedang berjalan pada fakultas ilmu komputer. Tujuan umum dari penelitian ini memberi suatu efisiensi atau peningkatan dalam pengolahan data diktat matakuliah dengan meningkatkan kompetensi mahasiswa terhadap jurusannya, tujuan khususnya untuk membuat sistem informasi berbasis online dalam pengumpulan RPKPS sehingga terintegrasi dengan baik dan disesuaikan dengan kurikulum yang sedang berjalan pada fakultas ilmu komputer, hanya dengan mengakses internet dan mengakses website dengan mudah, tidak memerlukan waktu yang lama.
\end{abstract}

Kata kunci: RPKPS, Sistem Informasi, Program Studi.

\begin{abstract}
Computer-based information is very influential in the world of work, as well as web-based information systems are used as a means of information enhancement. Utilization will facilitate a job as well as data processing faster, the decision will be taken more precisely, saving time and cost. In addition, web-based information systems can also be an efficient means of promotion and information resources that can be accessed by Internet users who are increasingly widespread. In the Faculty of Computer Science, the absence of media as a means of gathering RPKPS while the application of the computer and internet and resources already exist, so difficult in adjusting diktat subjects given lecturers against the competence of the study program and for the development of the competence of the study program. The method used by collecting existing data and analyze problems in the collection and adjustment of RPKPS by adjusting to the current curriculum on the faculty of computer science. The general purpose of this study provides an efficiency or improvement in the processing of data dictate course by improving the competence of students towards the department, the specific purpose to create an
\end{abstract}


online information-based system in the collection of RPKPS so well integrated and adapted to the current curriculum on the faculty of computer science, only By accessing the internet and Accessing website easily does not require a long time

Keywords: RPKPS, Information System, Study Program

\section{Pendahuluan}

Sistem informasi berbasis komputer sangat berpengaruh pesat dalam dunia kerja, begitu juga halnya sistem informasi berbasis web dimanfaatkan sebagai sarana peningkatan informasi. Pemanfaatan tersebut akan mempermudah suatu pekerjaan seperti halnya pengolahan data lebih cepat, keputusan yang akan diambil lebih tepat, menghemat waktu dan biaya. Selain itu, sistem informasi yang berbasis web juga dapat menjadi sarana promosi yang efesien dan sumber informasi yang dapat diakses oleh pengguna internet yang semakin lama semakin luas. Pada fakultas ilmu komputer belum adanya media sebagai sarana dalam pengumpulan RPKPS secara online matakuliah sementara sumber daya sudah ada, sehingga susah dalam mengolah data, baik untuk bahan ajar yang disampaikan dosen pengampu matakuliah maupun menyesuaikan diktat mata kuliah yang diberikan dosen pengampu terhadap kompetensi program studi dan untuk pengembangan kurikulum.

Rancangan program kegiatan pembelajaran semester atau RPKPS adalah panduan bagi dosen untuk mengampu matakuliah kepada mahasiswa sehingga target yang diinginkan program studi sesuai dengan apa yang menjadi kompetensi dari program studi. Hal ini juga perlu untuk mengembangkan kurikulum yang ditetapkan oleh program studi. Sehingga hal ini juga perlu untuk peningkatan mutu dosen dan mahasiswa. Adapun metode yang digunakan dengan mengumpulkan data-data yang ada dan menganalisa permasalahan dalam pengumpulan dan penyesuaian RPKPS dengan menyesuaikan kurikulum yang sedang berjalan pada fakultas ilmu komputer.

Permasalahan tersebutlah yang akan coba diangkat penulis. Dengan adanya perkembangan teknologi informasi lahirlah sebuah produk berupa aplikasi berbasis web. Dengan memanfaatkan media tersebut untuk menghitung ketepatan dalam proses kompetensi di program studi. Dalam topik ini penulis akan memanfaatkan web tersebut sebagai media data maupun komunikasi antara dosen yang mengampu matakuliah dengan program studi. Sehingga melalui penelitian ini diharapkan bisa menjadi tolak ukur ketepatan program studi yang ada pada fakultas ilmu komputer untuk mengembangkan kurikulum berdasarkan kompetensinya.

Yang menjadi rumusan masalah dalam penelitian ini adalah sebagai berikut:

Bagaimana merancang dan membangun aplikasi berbasis online sebagai sarana program studi untuk menyesuaikan bahan ajar yang disampaikan dosen pengampu mata kuliah dengan kompetensi program studi?

Bagaimana memanfaatkan aplikasi berbasis online dengan menggunakan database sebagai pengolahan data elektronik sebagai monitoring pengumpulan RPKPS mata kuliah untuk penyesuaian kurikulum program studi?

\section{Metode penelitian}

Dalam artikel ini menggunakan metode pengumpulan data dan metode pengembangan sistem sebagai berikut :

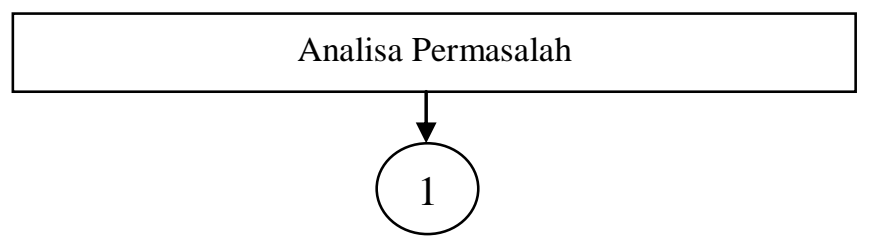




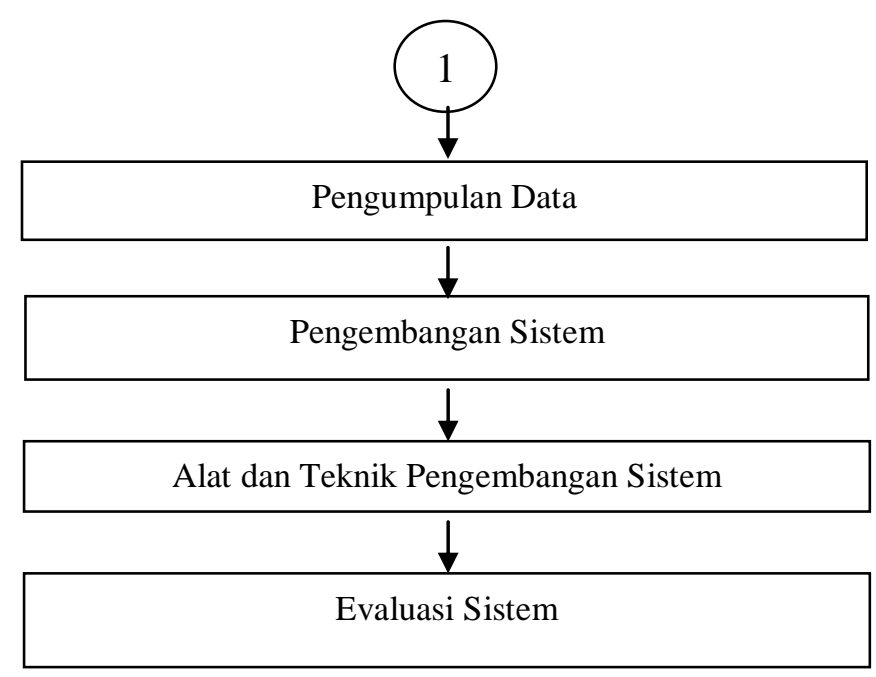

Gambar 1. Metode penelitian

\section{Jenis Penelitian}

Menurut jenisnya maka data yang digunakan dalam penelitian ini terdiri dari data primer dan data sekunder.

a. Data primer adalah data yang diperoleh langsung dari sumbernya, yaitu dengan melakukan wawancara terhadap informan yang dijadikan tempat penelitian ini. Data primer diperoleh dari hasil wawancara dengan: dosen prodi sistem informasi fakultas ilmu komputer universitas lancing kuning.

b. Data sekunder adalah data yang diperoleh dari buku-buku literatur, jurnal, dokumendokumen,laporan, peraturan pemerintah, dll.

\section{Metode Pengumpulan Data}

a. Metode Kepustakaan

Merupakan teknik pengumpulan data dengan cara mempelajari referensi berupa dokumen atau berkas dan mengumpulkan data, peraturan perundang-undangan, buku, jurnal penelitian dsb, Melalui studi pustaka dilakukan kajian terhadap peraturan-peraturan perundangan yang terkait komunikasi publik daerah. Kebutuhan data-data yang mengungkapkan tentang indikator-indikator yang digunakan untuk pembuatan arsip data berbasis online.

b. Metode Observasi

Metode observasi merupakan metode penelitian dimana, peneliti melakukan pengamatan/melihat dan meneliti langsung ke obyek penelitian tentang seluruh aktifitas yang berhubungan dengan maksud penelitian, Dengan menganalisa mengevaluasi sistem yang sedang berjalan dan memberikan solusi melalui sistem informasi yang akan dibangun sehingga dapat lebih bermanfaat.

c. Metode Wawancara

Wawancara merupakan percakapan antara peneliti dengan informan. Peneliti disini yang berharap mendapatkan informasi, sedangkan informan adalah seseorang yang diasumsikan mempunyai informasi penting tentang suatu obyek. Wawancara dilakukan langsung kepada ketua program studi sistem informasi universitas lancing kuning.

\section{Metode Pengembangan Sistem}

Pengembangan sistem dapat berarti menyusun suatu sistem yang baru untuk menggantikan sistem yang lama secara keseluruhan atau memperbaiki sistem yang telah ada. 
Sedangkan tahapan utama siklus hidup pengembangan sistem terdiri dari : metode pengembangan terstruktur dengan pendekatan siklus hidup pengembangan sistem (System Development Life Cycle atau SDLC). Terdiri dari beberapa fase antara lain sebagai berikut :

a. Perencanaan (Planning)

Pada tahap ini lebih fokus pada penafsiran kebutuhan dan diagnosa masalah dengan mendefinisikan sasaran dan tujuan dari sistem yang akan dibangun.

b. Analisa Sistem (System Analysis)

Pada fase ini dilakukan analisa terhadap sistem yang ada dengan metode yang digunakan yaitu metode wawancara dengan pihak-pihak yang terkait dan melakukan pengamatan terhadap kondisi pemda yang menjadi ruang lingkup penelitian. Pada fase ini meliputi: menentukan obyek, mempelajari organisasi, menganalisis kebutuhan output, menganalisis kebutuhan input, evaluasi efektifitas sistem.

c. Perancangan Sistem (System design)

Dalam merancang sistem ini berdasar pada kebutuhan dan masalah yang dihadapi pada obyek penelitian. Pada fase ini meliputi perancangan basis data, perancangan antar muka pengguna, kebutuhan perangkat keras, perancangan jaringan, kebutuhan perangkat lunak.

d. Implementasi Sistem (System Implementation)

Setelah melalui tahapan requirement, analysis dan design, maka seluruh sistem siap untuk diimplementasikan. Dalam tahapan implementasi ada beberapa tugas yang dijalankan diantaran mengimplementasikan design dalam komponen-komponen, souce code, script, executable sebagainya.

e. Operasi dan pemeliharaan sistem (System operation and maintenance). Pada tahap ini dilakukan pelatihan terhadap pengguna dan evaluasi terhadap sistem yang berjalan,apabila ada kekurangan maupun kesalahan diadakan perbaikan dan perawatan.

\section{Alat dan Teknik Pengembangan Sistem}

Metodologi pengembangan sistem terstruktur membutuhkan alat dan teknik. Alat yang digunakan dalam suatu metodologi umumnya berupa gambar atau diagram atau grafik agar lebih mudah dimengerti. Selain berbentuk gambar, alat yang digunakan juga tidak berupa gambar misalnya kamus data, struktur inggris, atau formulir-formulir untuk mencatat atau menyajikan data.

Alat-alat pengembangan sistem yang berbentuk grafik diantaranya :

a. Diagram HIPO (Hierarchy plus Input-Proces-Output).

b. Diagram aliran data (DFD atau Data Flow diagram).

c. Diagram keterhubungan entitas (ERD atau Entity Relationship Diagram).

d. Diagram Perubahan status (STD atau State Transition Diagram).

e. Structured Chart.

Alat yang berbentuk grafik yang umum dapat digunakan pada semua metodologi antara lainbagan alir sistem, bagan alir program, bagan alir proses, bagan organisasi dll.

\section{Hasil dan pembahasan}

\section{Pengumpulan data tabulasi program Studi terhadap permasalahan.} dibawah ini.

Adapun data yang telah dikumpulkan dalam penelitian ini dapat dilihat pada tabel

Tabel 1. Tabulasi kuisioner program studi pada permasalahan

\begin{tabular}{|c|c|c|c|c|c|c|c|c|c|c|c|c|c|c|c|c|}
\hline Soal & $\mathbf{1}$ & $\mathbf{2}$ & $\mathbf{3}$ & $\mathbf{4}$ & $\mathbf{5}$ & $\mathbf{6}$ & $\mathbf{7}$ & $\mathbf{8}$ & $\mathbf{9}$ & $\mathbf{1 0}$ & $\mathbf{1 1}$ & $\mathbf{1 2}$ & $\mathbf{1 3}$ & $\mathbf{1 4}$ & $\mathbf{1 5}$ & Jumlah \\
\hline 1 & 3 & 3 & 3 & 4 & 3 & 4 & 3 & 2 & 1 & 1 & 1 & 3 & 1 & 2 & 2 & 36 \\
\hline 2 & 4 & 3 & 4 & 4 & 4 & 5 & 5 & 5 & 2 & 3 & 4 & 4 & 4 & 3 & 4 & 58 \\
\hline 3 & 5 & 4 & 5 & 3 & 4 & 5 & 5 & 5 & 2 & 2 & 2 & 3 & 2 & 1 & 3 & 51 \\
\hline
\end{tabular}




\begin{tabular}{|c|c|c|c|c|c|c|c|c|c|c|c|c|c|c|c|c|}
\hline 4 & 2 & 2 & 3 & 4 & 2 & 3 & 4 & 4 & 1 & 2 & 1 & 4 & 1 & 1 & 1 & 35 \\
\hline 5 & 1 & 2 & 4 & 3 & 1 & 4 & 4 & 5 & 1 & 1 & 1 & 1 & 1 & 1 & 1 & 31 \\
\hline 6 & 4 & 2 & 5 & 4 & 3 & 4 & 4 & 4 & 1 & 1 & 2 & 3 & 2 & 2 & 2 & 43 \\
\hline 7 & 4 & 3 & 5 & 5 & 5 & 5 & 2 & 5 & 2 & 2 & 1 & 5 & 2 & 2 & 4 & 52 \\
\hline 8 & 4 & 3 & 5 & 4 & 4 & 5 & 4 & 5 & 1 & 1 & 1 & 3 & 1 & 1 & 4 & 46 \\
\hline 9 & 2 & 2 & 5 & 4 & 2 & 4 & 5 & 5 & 1 & 1 & 2 & 4 & 2 & 2 & 2 & 43 \\
\hline 10 & 2 & 2 & 2 & 4 & 3 & 4 & 4 & 5 & 2 & 2 & 2 & 4 & 2 & 2 & 2 & 42 \\
\hline Total & 48 & 37 & 61 & 58 & 47 & 64 & 61 & 65 & 21 & 23 & 26 & 50 & 29 & 25 & 36 & 651 \\
\hline Mean & 3.2 & 2.5 & 4.1 & 3.9 & 3.1 & 4.3 & 4.1 & 4.3 & 1.4 & 1.5 & 1.7 & 3.3 & 1.9 & 1.7 & 2.4 & 35.4 \\
\hline
\end{tabular}

Tabel kuisioner menjelaskan permasalahan program studi yang terjadi dalam pengembangaan program studi karena belum adanya media yang bisa digunakan oleh program studi dalam pengontrolan RPKPS matakuliah yang dikumpulkan oleh dosen dalam menyampaikan matakuliah kepada mahasiswa apakah sudah cocok terhadap kompetensi program studi.

\section{Rancangan Sistem yang baru}

Penulis merancang suatu sistem dengan menggunakan metode pengembangan sistem development lyfe cycle (SDLC) dengan alat bantu sistem pendekatan unified modelling language (UML).

\section{Usecase Diagram}

Usecase Diagram menjelaskan gambaran actor-aktor yang terlibat dalam penggunaan sistem yang akan dibangun, dapat dilihat pada gambar dibawah ini:

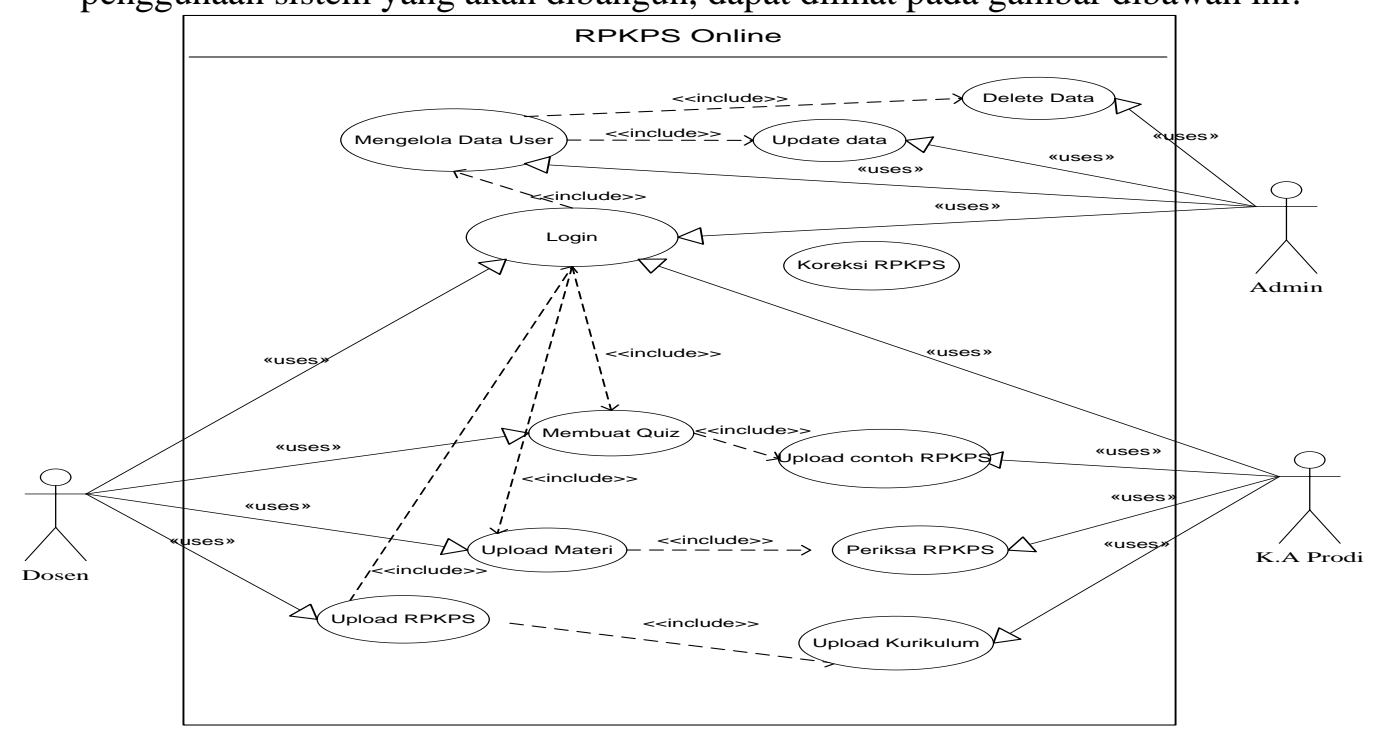

Penjelasan:

\section{Gambar 2. Usecase Diagram}

1. Dalam pengembangan sistem ada 3 aktor yaitu : Admin, Dosen dan K.A prodi.

2. Admin bertugas mengontrol sistem, mengisi content, mengelola akun pengguna sistem, maintenance aplikasi dalam pengumpulan RPKPS.

3. Dosen bertugas sebagai upload RPKPS matakuliah kedalam sistem, mengupload materi bahan ajar.

4. K.A Prodi mengontrol apakah RPKPS yang di upload dosen yang mengajar apakah sudah cocok terhadap kompetensi yang diharapkan oleh program studi.

5. Semua aktor harus login terlebih dahulu sebelum melakukan kegiatan didalam sistem. 


\section{Activity Diagram}

Activity Diagram menjelaskan bagaimana alur dari sistem yang dikembangkan dalam pengumpulan RPKPS matakuliah berbasis online, dapat dilihat pada gambar dibawah ini:

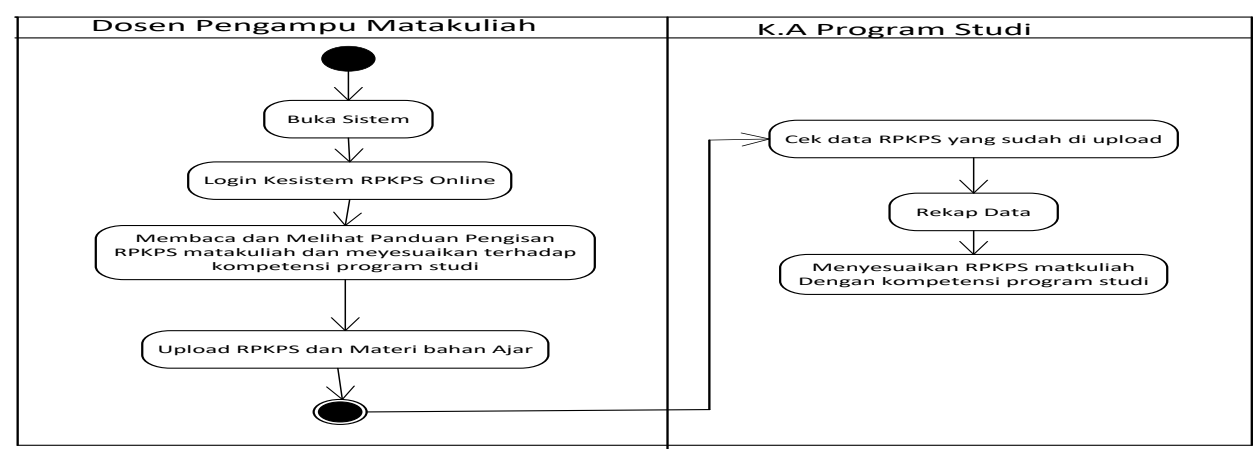

Penjelasan:

\section{Gambar 3. Activity Diagram}

1. Pada activity diagram menjelaskan alur dosen dalam pengumpulan RPKPS matakuliah terhadap sistem yang berbasis online.

2. Dosen pengampu juga membaca dan melihat panduan dalam pembuatan format RPKPS lalu menyesuaikan dengan panduan yang diberi oleh K.A program studi.

3. K.A Prodi mengontrol apakah dosen pengampu matkuliah sudah mengupload RPKPS dan materi bahan ajar.

4. K.A Prodi menyesuaikan RPKPS matkuliah yang sudah di upload apakah sudah sesuai dengan kompetensi yang diharapkan oleh program studi.

\section{Class Diagram}

Class Diagram menjelaskan entitas dan atribut didalam sistem pengumpulan RPKPS online, dapat dilihat pada gambar di bawah ni:

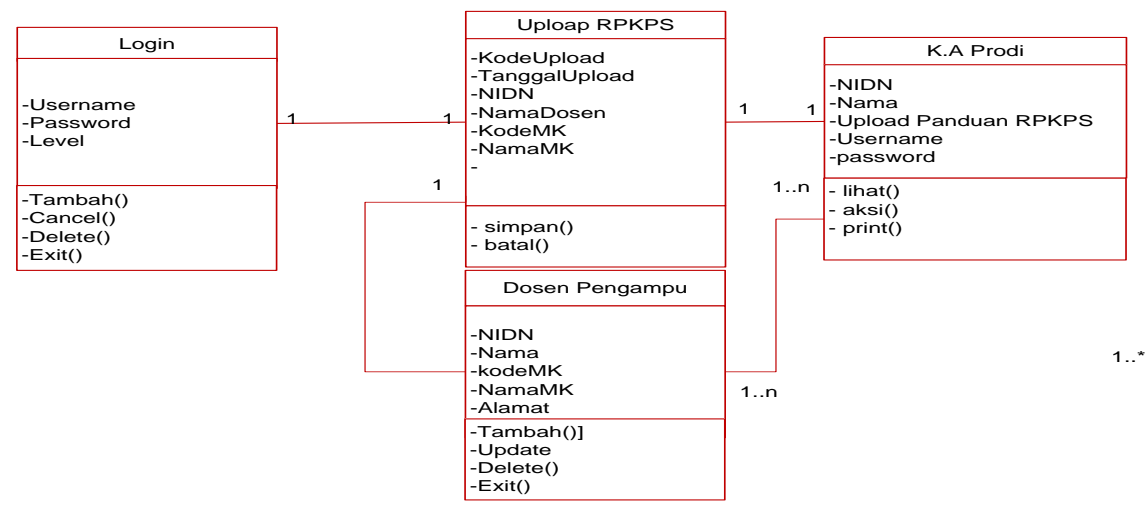

Penjelasan:

\section{Gambar 4. Class Diagram}

1. Pada class diagram ada 4 entitas dalam sistem pengumpulan RPKPS online yaitu: Login, upload RPKPS, K.A Prodi, dan Dosen Pengampu.

2. Masing-masing entitas memiliki atribut yang merupakan penjelasan dari entitas tersebut.

3. Pada class diagram juga menjelaskan integritas aliran data dalam sistem yang dikembangkan.

Interface sistem yang baru

Pada tampilan sitem yang baru yang telah dibangun berdasarkan perancangan sebelumnya dari usecase diagram, activity diagram, dan class diagram. 


\section{Halaman Menu Utama}

Pada sistem yang telah dibuat halaman menu utama program dalam pengumpulan RPKPS matkuliah dapat dilihat pada gambar dibawah ini:

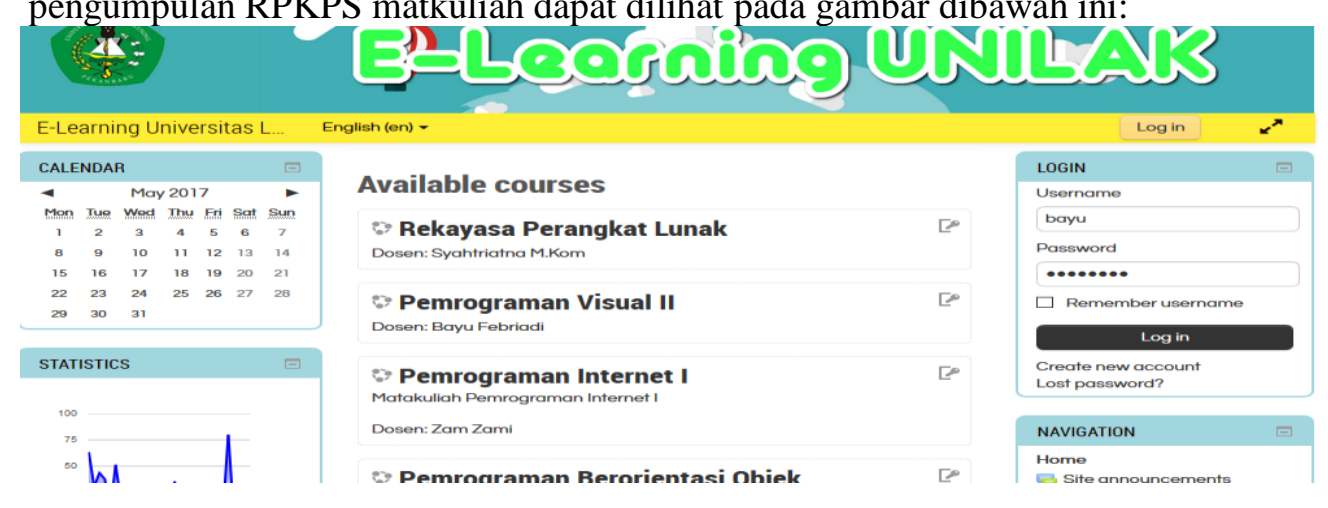

\section{Gambar 5. Halaman menu Utama}

\section{Halaman login sistem}

Pada sistem yang telah dibuat halaman login program dalam pengumpulan RPKPS matakuliah online dapat dilihat pada gambar dibawah ini:

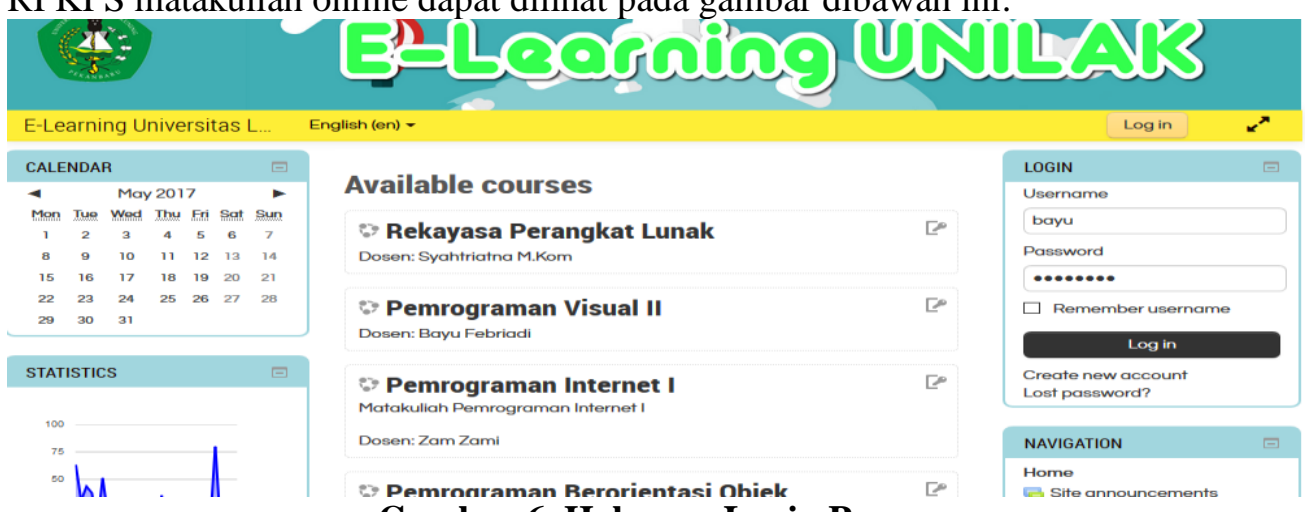

\section{Halaman Upload RPKPS Matakuliah}

\section{Gambar 6. Halaman Login Program}

Pada sistem yang telah dibuat halaman upload RPKPS dapat dilihat pada gambar dibawah ini:

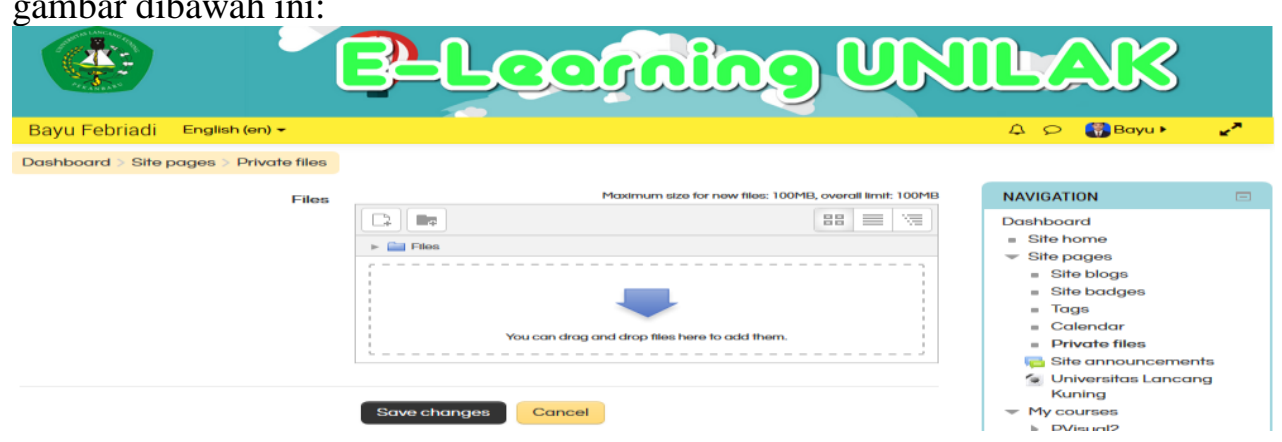

Gambar 7. Halaman Upload RPKPS

\section{Halaman Koreksi RPKPS Matakuliah}

Pada sistem yang telah dibangun halaman koreksi RPKPS matakuliah yang sudah di upload dosen pengampu oleh K.A program studi, dapat dilihat pada gambar dibawah ini: 


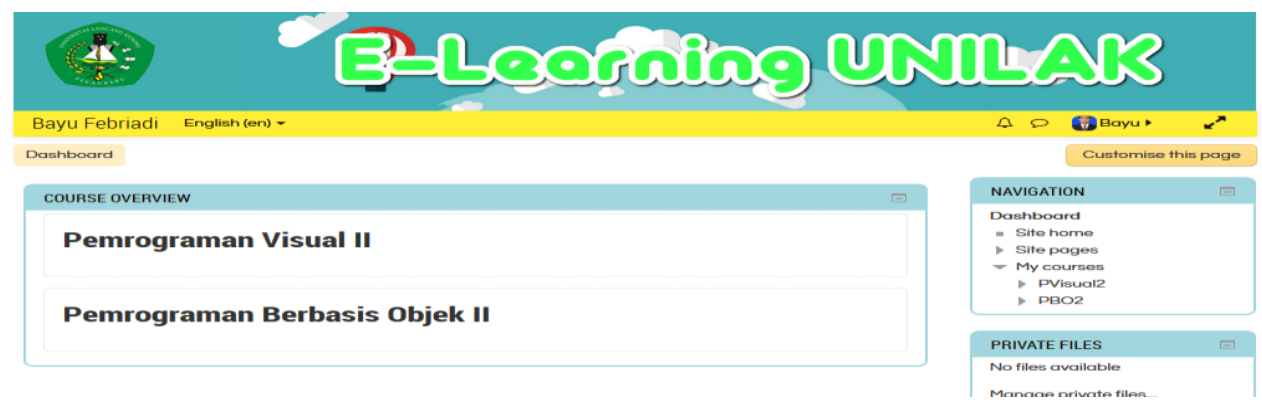

Gambar 8. Halaman Koreksi RPKPS

\section{Pengolahan Data kuisioner}

Setelah implementasi program RPKPS online pada program studi informasi fakultas ilmu komputer, kemudian penulis kembali melakukan pengolahan data kuisioner yang ditujukan terhadap dosen pengampu matakuliah dan pada ketua program studi. Adapun hasil kuisioner yang di olah dapat dilihat pada gambar dibawah ini:

2. Tabulasi data kuisioner terhadap dosen pengampu matkuliah

\begin{tabular}{|c|c|c|c|c|c|c|c|c|c|c|c|c|c|c|c|c|}
\hline Soal & $\mathbf{1}$ & $\mathbf{2}$ & $\mathbf{3}$ & $\mathbf{4}$ & $\mathbf{5}$ & $\mathbf{6}$ & $\mathbf{7}$ & $\mathbf{8}$ & $\mathbf{9}$ & $\mathbf{1 0}$ & $\mathbf{1 1}$ & $\mathbf{1 2}$ & $\mathbf{1 3}$ & $\mathbf{1 4}$ & $\mathbf{1 5}$ & Jumlah \\
\hline 1 & 3 & 3 & 3 & 4 & 3 & 4 & 3 & 2 & 1 & 1 & 1 & 3 & 1 & 2 & 2 & 36 \\
\hline 2 & 4 & 3 & 4 & 4 & 4 & 5 & 5 & 5 & 2 & 3 & 4 & 4 & 4 & 3 & 4 & 58 \\
\hline 3 & 5 & 4 & 5 & 3 & 4 & 5 & 5 & 5 & 2 & 2 & 2 & 3 & 2 & 1 & 3 & 51 \\
\hline 4 & 2 & 2 & 3 & 4 & 2 & 3 & 4 & 4 & 1 & 2 & 1 & 4 & 1 & 1 & 1 & 35 \\
\hline 5 & 1 & 2 & 4 & 3 & 1 & 4 & 4 & 5 & 1 & 1 & 1 & 1 & 1 & 1 & 1 & 31 \\
\hline 6 & 4 & 2 & 5 & 4 & 3 & 4 & 4 & 4 & 1 & 1 & 2 & 3 & 2 & 2 & 2 & 43 \\
\hline 7 & 4 & 3 & 5 & 5 & 5 & 5 & 2 & 5 & 2 & 2 & 1 & 5 & 2 & 2 & 4 & 52 \\
\hline 8 & 4 & 3 & 5 & 4 & 4 & 5 & 4 & 5 & 1 & 1 & 1 & 3 & 1 & 1 & 4 & 46 \\
\hline 9 & 2 & 2 & 5 & 4 & 2 & 4 & 5 & 5 & 1 & 1 & 2 & 4 & 2 & 2 & 2 & 43 \\
\hline 10 & 2 & 2 & 2 & 4 & 3 & 4 & 4 & 5 & 2 & 2 & 2 & 4 & 2 & 2 & 2 & 42 \\
\hline Total & 48 & 37 & 61 & 58 & 47 & 64 & 61 & 65 & 21 & 23 & 26 & 50 & 29 & 25 & 36 & 651 \\
\hline Mean & 3.2 & 2.5 & 4.1 & 3.9 & 3.1 & 4.3 & 4.1 & 4.3 & 1.4 & 1.5 & 1.7 & 3.3 & 1.9 & 1.7 & 2.4 & 40.4 \\
\hline
\end{tabular}

Dari data tabel terlihat dosen pengampu merasa terbantu dengan adanya sistem pengumpulan RPKPS online pada program studi informasi sebesar dari sebelum penerapan sistem degan ratarata 35,4 point menjadi 40,4 Point

3. Tabulasi data kuisioner terhadap program studi

\begin{tabular}{|c|r|l|l|l|l|l|l|l|l|l|r|r|r|r|r|r|}
\hline Soal & $\mathbf{1}$ & $\mathbf{2}$ & $\mathbf{3}$ & $\mathbf{4}$ & $\mathbf{5}$ & $\mathbf{6}$ & $\mathbf{7}$ & $\mathbf{8}$ & $\mathbf{9}$ & $\mathbf{1 0}$ & $\mathbf{1 1}$ & $\mathbf{1 2}$ & $\mathbf{1 3}$ & $\mathbf{1 4}$ & $\mathbf{1 5}$ & Jumlah \\
\hline 1 & 3 & 3 & 3 & 4 & 3 & 4 & 3 & 2 & 4 & 4 & 5 & 3 & 5 & 2 & 2 & 50 \\
\hline 2 & 4 & 3 & 4 & 4 & 4 & 5 & 5 & 5 & 2 & 3 & 4 & 4 & 4 & 3 & 4 & 58 \\
\hline Total & 7 & 6 & 7 & 8 & 7 & 9 & 8 & 7 & 6 & 7 & 9 & 7 & 9 & 5 & 6 & 108 \\
\hline Mean & 3.5 & 3 & 3.5 & 4 & 3.5 & 4.5 & 4 & 3.5 & 3 & 3.5 & 4.5 & 3.5 & 4.5 & 2.5 & 3 & 54 \\
\hline
\end{tabular}

Dari data tabel pengolahan kuisioner terlihat bahwa program studi merasa terbantu dengan adanya penerapan pengumpulan RPKPS matakuliah berbasis online pada program studi informasi fakultas ilmu komputer dengan rata-rata 34 point menjadi 54 point. 


\section{Kesimpulan dan saran Kesimpulan}

Setelah dilakukan kegiatan penelitian pada program studi informasi fakultas ilmu komputer maka penulis dapat menyimpulkan bahwa:

1. Kegiatan penelitian pengumpulan RPKPS online dapat membantu dosen dan program studi dalam pengolahan data untuk peningkatan ketepatan komptensi program studi yang diberikan sebesar 4,8 point, dimana sebelum dilakukan kegiatan pengetahuan karyawan dalam pengolahan data kuisioner dngan rata-rata 4,27 menjadi 4,75.

2. Program studi sangat terbantu dengan adanya pengumpulan RPKPS online yaitu pada bagian pengontrolan RPKPS yang lebih tinggi dengan nilai rata-rata 4,5 point, sedangkan yang paling rendah padas layanan pengambilan dengan nilai rata-rata 2,3 point.

\section{Saran}

Setelah dilakukan kegiatan pengabdian pada kantor kesehatan kelas 2 pekanbaru maka penulis memberikan saran bahwa:

1. Diharapkan dalam ujicoba pengumpulan RPKPS Online, dosen dan program studi memberikan sosialisasi atau menjelaskan dalam pengisian kuisoner kepada dosen yang akan mengupload RPKPS kedalam sistem.

2. Diharapkan dalam pengambilan keputusan untuk peningkatan program studi harus menggunakan data responden yang lebih banyak sehingga menghasilkan hasil yang lebih tepat, Karena dalam kegiatan ini hanya menggunakan 15 data responden dalam 2 hari ujicoba.

\section{Daftar pustaka}

[1] Agung Baitullah Hikmah, M.Kom, Deddy Supriadi, M. K. (2014). Implementasi Elearning sebagai Komplemen dan Blanded Learning Untuk Meningkatkan Motivasi dan Hasil Belajar Pada Matakuliah Enterprise Resources Planning

[2] Haris Pamugar, Wing wahyu wiyono, Cahyono T2 (2014). Model Evaluasi dan Penerimaan sistem informasi e-learning Pada lembaga Diklat Pemerintahan (Issn 2407765, Scientific Journal of Informatics Vol. 1, No. 1, Mei 2014)

[3] Hanson. 2000. Sejarah Pemograman berbasis Web. Yogyakarta: Andi offset

[4] Hardjono. 2006. Pengenalan Sistem Informasi Berbasis Web. Jakarta: Erlangga

[5] Kadir, Abdul. 2005. Pengenalan Sistem Informasi. Jakarta, Yogyakarta: Andi

[6] Liang Gie.2000, Administrasi perkantoran Modern. Bandung: Informatika

[7] Nugroho, Andi.2004. Database Berbasis DBMS dalam Pengolahan Data Terintegrasi. Bandung: Informatika

[8] Oneto, Erima. 2008. Cascadading Management Style Sebagai media Program Berbasis Web. Bandung: Informatika

[9] Seprida hanum harahap (2013). Pemanfaatan E-learning berbasis LCMS Moodle sebagai Media Pembelajaran Untuk Matakuliah Sistem Informasi Akuntansi ( Issn 2407-765, Scientific Journal of Informatics Vol. 1, No. 2, Mei 2013)

[10] Tri Dharmayanti, Yudhi Setiani , Boedhi Oetojo (2012). E-learning Pada Pendidikan Jarak Jauh: Konsep Yang mengubah Metode Pembelajaran di perguruan tinggi indonessia (Issn 2407-765, Scientific Journal of Informatics Vol. 1, No. 1, Mei 2014) 